\title{
SIKLUS HIDUP PRODUK RUJAK SIMPANG JODOH
}

\author{
Riska Ayu Rivansyah \\ Mumuh Mulyana \\ Universitas Terbuka
}

\section{Ringkasan}

Daur hidup produk (PLC= Product Life Cycle) merupakan konsep yang penting dalam pemasaran yang dapat memberikan gambaran dinamika kompetitif suatu produk yaitu tahaptahap yang berbeda dalam sejarah penjualannya. Tiap tahapan produk mempunyai tantangan yang berbeda dan dapat memberikan kontribusi laba yang berbeda sehingga dibutuhkan strategi pemasaran yang handal. Tahapan produk dapat dibagi menjadi empat yaitu perkenalan, pertumbuhan, kedewasaan, dan penurunan. Rujak Ulek SURI Simpang Jodoh Medan yang beroperasi sejak tahun 2000 telah memasuki tahapan dalam siklus hidup produk.

\section{Hasil Observasi}

1. Produk apa yang dijual

Jawab: Produk yang dijual adalah Rujak Simpang Jodoh

2. Berapa Harga jual produk

Jawab: 1 Bungkus Rp. 15.000

3. Bentuk Promosi apa yang dilakukan

Jawab : tidak ada bentuk promosi

4. Bentuk pendistribusian yang dilakukan.

Jawab: Layanan yang dilakukan adalah melalui layanan antar pemesanan (online) dan bisa beli langsung ditempat

5. Berjualan sejak tahun berapa

Jawab: sejak tahun 2000

6. Jumlah karyawan yang terlibat dalam operasional bisnis

Jawab: 1 orang

7. Omset per harinya berapa

Jawab: Rp. 1.500.000

8. Siapa saja Konsumen yang membeli produknya

Jawab : masyarakat setempat dan lainnya 
9. Buka jam berapa dan tutup jam berapa?

Jawab : Buka jam $09.00-00.00$ WIB

10. Usaha ini milik siapa?

Jawab : milik sendiri

Di bagian akhir laporan observasi Anda, tuliskan hasil analisis Anda dengan menjawab pertanyaan berikut ini :

a. Merujuk pada diagram Product Life Cycle, menurut Anda berada pada tahap mana bisnis tersebut? Jelaskan Alasan Anda!

Menurut saya, bisnis ini memasuki tahap pertumbuhan (growth) karena, setiap harinya mengalami peningkatan konsumen yang datang untuk membeli produk tersebut.

b. Sebutkan strategi apa saja yang perlu dilakukan agar bisnis tersebut berada pada tahap maturity (kedewasaan) yang relatif panjang?

Strategi yang dilakukan agar berada di tahap maturity (kedewasaan) yaitu dengan :

- Modifikasi pasar, dengan konsep meanrik perhatian orang yang bukana pemakai, memasuki segmen pasar baru, dan merebut pelanggan pesaing.

- Modifikasi produk, meningkatkan volume penjulan dengan cara memodifikasi karakteristik produk melalui peningkatan mutu produk, peningkatan ciri-ciri atau fiturfitur produk dan peningkatan model produk.

- Modifikasi bauran pasar, dengan diskon harga, distribusi, iklan, sales, personil penjualan dan pelayanan.

c. Sejauh mana bisnis tersebut dalam memanfaatkan digital marketing (social media, web, dan sejenisnya)

Bisnis tersebut menggunakan digital marketing dengan layanan gojek online. Dengan menggunakan digital marketing ini, bisnis dapat berjalan dengan mudah dan lancar. Selanjutnya, menjadi sarana penghubung yang baik dengan konsumen dan keakraban antara penjual dengan pelanggan pun bisa semakin mudah terjalin.

\section{Gambar/ Photo Pedagang Rujak Simpang Jodoh Medan}



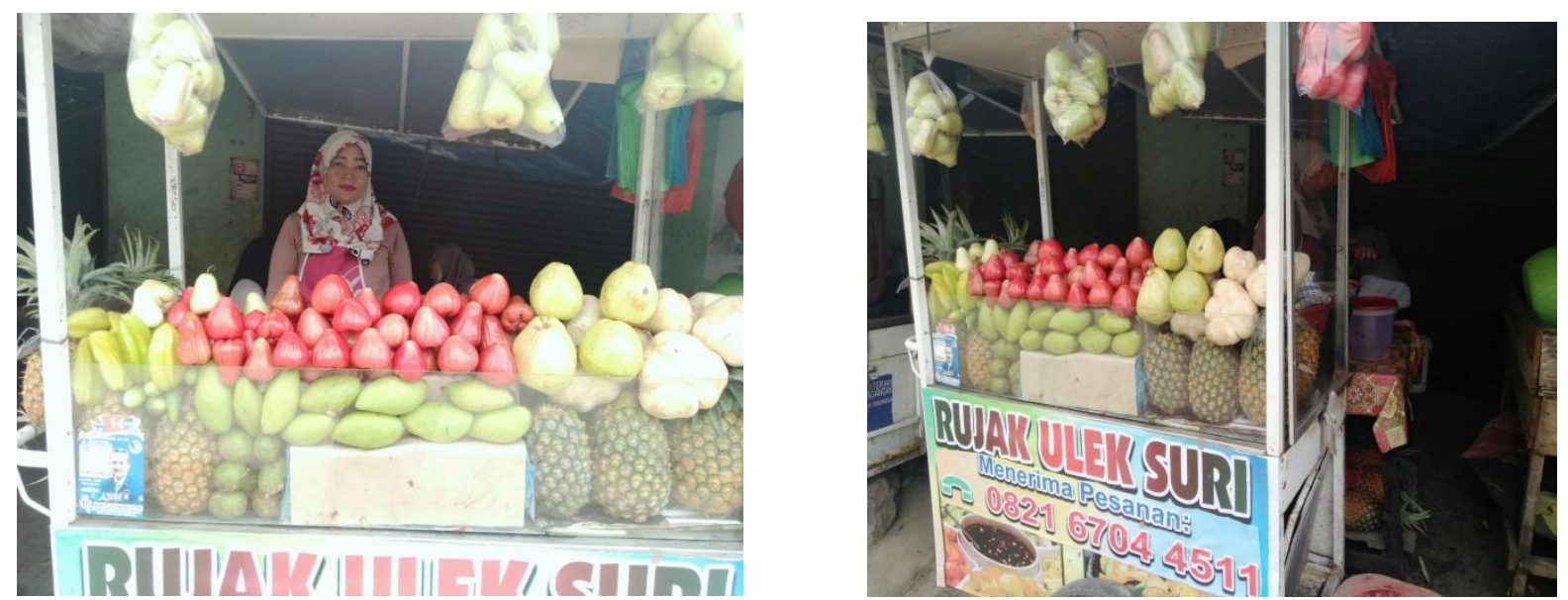

\section{Referensi :}

Pauziah, P. and Mulyana, M., 2018. Formulation of The Green Marketing Development Strategy for the Body Shop Botani Square Bogor. In THE INTERNATIONAL CONFERENCE ON ACCOUNTING AND MANAGEMENT SCIENCE (p. 171).

Hidayat, L., Mulyana, M. and Effendy, M., 2018. Membangun Kepuasan Mahasiswa Pengguna Laboratorium Komputer. JAS-PT Jurnal Analisis Sistem Pendidikan Tinggi, 1(2), pp.93101.

Sulistiono, S., Nurendah, Y. and Mulyana, M., 2019. Mengukur Minat Studi Siswa SMA dan SMK di Kota Bogor Pada Program Studi Kewirausahan. JAS-PT Jurnal Analisis Sistem Pendidikan Tinggi, 3(1), pp.1-12.

NOVITASARI, R. and Mulyana, M., 2019. APLIKASI BAURAN PEMASARAN PADA BISNIS KECIL-STUDI KASUS PADA BARRACKS. CAFE.

Mulyana, M., 2019. MENGANALISIS PERILAKU KONSUMEN.

Mashadi, M. and Irawan, R., 2017. Model Struktural Minat Mahasiswa Berkarir di Bidang Perbankan Syariah Sebagai Dasar Pengembangan Proses Pembelajaran. JAS-PT Jurnal Analisis Sistem Pendidikan Tinggi, 1(1), pp.1-10.

Binangkitsari, L. and Sulistiono, S., 2018. The Influence of Brand Equity Elements on Purchase Decision and Its Imlication on Customer Loyalty. In THE INTERNATIONAL CONFERENCE ON ACCOUNTING AND MANAGEMENT SCIENCE (p. 305).

Maulana, M.A, Iriyadi, I. and Nurjanah, Y. 2018. Financial Reporting for Micro Small and Medium Enterprises Towards Industrial Revolution Era 4.0. In THE INTERNATIONAL CONFERENCE ON ACCOUNTING AND MANAGEMENT SCIENCE (p. 32-38).

Rosita, S.I., 2014. Pengaruh Sistem Bagi Hasil Deposito Mudharabah Terhadap Minat Nasabah Berinvestasi Pada Bank Syariah. Jurnal Ilmiah Akuntansi Kesatuan, 2(1), pp.085-098.

Rosita, S.I. and Rahman, A., 2011. EVALUASI PENERAPAN PEMBIAYAAN MUDHARABAH DAN PENGARUHNYA TERHADAP LABA PERUSAHAAN Studi Kasus pada PT Bank Muamalat Indonesia Tbk, Cabang Bogor. Jurnal Ilmiah Ranggagading, 11(1), pp.57-64.

Pamungkas, B., Ibtida, R. and Avrian, C., 2018. Factors influencing audit opinion of the Indonesian municipal governments' financial statements. Cogent Business \& Management, 5(1), p.1540256.

Djanegara, M.S., Mulyani, S., Putra, D.M., Zahra, N.A.K. and Mauludina, M.A., 2018. The effect of institutionalization isomorphic pressures and the role of knowledge management 
on investment decisions of the accounting information systems. Polish Journal of Management Studies, 18.

Marjuki, M. and Fadillah, A., 2014. Pengaruh Tenaga Penjualan dan Citra Perusahaan Terhadap Keputusan Pembelian. Jurnal Ilmiah Manajemen Kesatuan, 2(1). 